\title{
Irrigation erosion of irrigated soils in the foothills of southern Kazakhstan
}

\author{
Abdulla S SAPAROV ${ }^{1}$, Enadiy K MIRZAKEEV ${ }^{1}$, Tatyana M SHARYPOVA ${ }^{1}$, Galymzhan A SAPAROV ${ }^{1}$, \\ Jilili ABUDUWAILI ${ }^{2 *}$ \\ ${ }^{1}$ Kazakh Research Institute of Soil Science and Agrochemistry named after Uspanov, Almaty 050060, Kazakhstan; \\ ${ }^{2}$ State Key Laboratory of Desert and Oasis Ecology, Xinjiang Institute of Ecology and Geography, Chinese Academy of Sciences, \\ Urumqi 830011, China
}

\begin{abstract}
This paper presented the results from the study of irrigation erosion of irrigated lands in southern Kazakhstan. The main purpose of the work is the conservation of the fertility of irrigated soils, and then the soils of the upper, middle and lower sections of the slopes at the experimental site were studied. Based on field investigations, authors studied the water resistance of aggregates of gray-brown soils and light gray soils before and after irrigation and qualitative indicators of changes in physical and chemical properties of structured soils in irrigation were determined by conventional methods of soil research. The results indicated that the changes in the physical properties of soils by using polymeric compounds created a fundamentally new opportunity to control water erosion of soils.
\end{abstract}

Keywords: irrigation erosion; furrow irrigation; structure-forming polymers; deformation of furrows; permissible water speed; aggregate water stability

Citation: Abdulla S SAPAROV, Enadiy K MIRZAKEEV, Tatyana M SHARYPOVA, Galymzhan A SAPAROV, Jilili ABUDUWAILI. 2013. Irrigation erosion of irrigated soils in the foothills of southern Kazakhstan. Journal of Arid Land, 5(2): 166-171.

The presence of various natural conditions and terrain types imposes different requirements for the location of irrigation farms and the elements of irrigation techniques in irrigated areas. More than $80 \%$ of southern Kazakhstan is irrigated lands. The development of irrigation erosion is related to poor irrigation system, big furrow slope, inappropriate irrigation methods and other related aspects. The improvement of these factors will contribute to the conservation of soil fertility, maintenance of soil productivity, economical use of irrigation water, and high and stable yields of crops in irrigated agriculture.

One reason of irrigation erosion is the imbalance of furrow slopes and intensity of irrigation streams. The second reason is the low water permeability and weak anti-erosion capacity of soils, which is associated with the weak structure of soils and destructive action of water. The third reason concerns the bumps on the surface of irrigated lands, which add to the unequal slopes in different parts of the furrows, and accelerate the process of water erosion during irrigation.

Methods of controlling irrigation erosion have not been sufficiently developed due to the lack of a unified scientific approach to understand the mechanism of erosion process and quantitative evaluation of the effectiveness of preventive measures under different soil and climatic conditions. The mechanism of irrigation erosion includes, on the one hand, the study of the ability of the water flow in the furrows to perform work on the separation and movement of topsoil particles, and on the other hand, the determination of the soil stability contrast to the force impact of irrigation water.

A perspective method of forming big-lump water-resistant topsoil layers on arable horizons is through the treatment with polymers for building soil structure. Studies of applying polymers for building soil structure in the control of water erosion have been first

*Corresponding author: Jilili ABUDUWAILI (E-mail: jilil@ms.xjb.ac.cn) Received 2012-05-28; revised 2012-09-20; accepted 2012-12-18

(C) Xinjiang Institute of Ecology and Geography, Chinese Academy of Sciences, Science Press and Springer-Verlag Berlin Heidelberg 2013 
conducted by Gusak (1961), Matyunin (1965) and Ismatov (1962), who reported high anti-erosion efficiencies. The effectiveness of this method of controlling irrigation erosion has been confirmed by Kaczynski et al. (1967), Khamdamov (1973), Kuznetsov (1981), Shadraimova (2002), Namzhilov et al. (2004), and Parakshina et al. (2010).

Erosion resistance of soils was evaluated by the wash-off speed of water movement to quantitatively reveal the function of contributing characteristics. These characteristics are integral indicators of the influence of water flows in the furrows on the intensity of erosion process.

\section{Study area}

The study of irrigation erosion was carried out in the irrigation area of Zadarinsky in Arys district of southern Kazakhstan, located at the right bank of the Syr Darya River in Central Asia. The climate of Kazakhstan is typically continental, characterized by big variations in meteorological conditions. In winter, the cold continental Siberian anticyclone with low temperature penetrates the southern regions of Kazakhstan. In spring, the temperature rises very quickly. It is hot and dry in summer, and autumn is characterized by variable weather and frequent occurrence of rainfalls.

\section{Methods}

In the experimental site, soil samples were collected on the upper, middle and lower parts of the slope. For comparing the water erosion of the irrigated lands, the control site of measuring water consumption and soil wash was chosen at the closed side of the irrigation channel.

At the experimental site with an area of $10 \mathrm{hm}^{2}$, the level of irrigation erosion and the change of the lateral and cross-sectional cut of furrows during the wash-off were determined by leveling survey before and after irrigation of crops. The steepness of the slope is a very important factor for drainage and soil erosion.

At the comparatively uniform flat slope $(\mathrm{i}=0.007)$ and a flow rate of $0.2 \mathrm{l} / \mathrm{s}$, cross-section of the furrow did not change and only a slight deformation of the bottom was observed $(1.5-2.0 \mathrm{~cm})$. At different slopes and water consumption in the fields with wavy mesorelief, the change in the furrow profiles took place due to the flushing of fine earth from the beginning part of the furrow and its accumulation in the ending part. The erosion intensity of furrows at all slopes and water expenditure showed a declining trend: during the first hour, it declined most significantly; during the second and third hours, it was slightly less; and after three hours of water passage, almost complete stabilization of the wash-off in the furrow took place.

Measuring of the soil wash was carried out during the whole irrigation process by taking water samples for measuring water opacity and water consumption. The sampling site for the measurement of water turbidity and the counting of suspended particles was at the end of the furrow. Hydrometric equipment with a thin wall was prepared. The water samples were taken from the stream which poured out from the weir at different intervals of $60,120,180$ and 300 minutes when the water got the end of the furrow. The soil drifts were filtered, dried, and weighed. The quantity of the soil and water that crossed the borders of the irrigated field was measured by the dumped water volume and average weight of the solid flow.

The intensity of the removal of soil particles during irrigation in the furrow was evaluated by taking water samples for turbidity measurement. The turbidity of water was determined from samples taken at the end of the furrow in $5,15,30,60,120,240$, and 1,440 minutes. Water consumption was measured during the whole experiment by using triangular drains in the head and tail parts of the furrow.

The wash-off materials were determined as following: grain size composition by pipette method with pre-treatment of sodium pyrophosphate Grabarov's modification; water resistance of the structure by $\mathrm{N}$. Savinov's method; humus by Tyurin's method; total nitrogen by Kjeldahl; available phosphorus by Machigin in Grabarov's modification with subsequent determination at the FEC-56 V; available potassium by Machigin method in Grabarov's modification with subsequent determination using flame photometer FLARNO 4; and the absorbed bases $(\mathrm{Ca}, \mathrm{Mg})$ by trilonometric method (Arinushkina, 1970).

An important factor of soil erosion resistance is the water resistance of the structure. It was determined that the most effective method of increasing and conserving the erosion resistance was the tillage of the 
surface layer of the furrow's bottom by forming polymers of $\mathrm{K}-4, \mathrm{~K}-9$, and $\mathrm{PGK}+\mathrm{AA}$. $\mathrm{PGK}+\mathrm{AA}$ is a copolymer of industrial humic acids with acrylamide (humic acids:monomer=10:1). Industrial humic acids, obtained by electrochemical oxidation, are dark brown powder, soluble in water. The preparation $\mathrm{PGK}+\mathrm{AA}$ was obtained by the Institute of Organic Synthesis and Carbon Chemistry, National Academy of Sciences of the Republic of Kazakhstan (Karagandy). For structuring in a production environment, the following synthetic water-soluble polymer products were recommended: polyacrylamide, hydrolyzed polyacrylonitrile, and polymers of a series of K (K-4 and K-9). The surface soil layer was sprayed with solutions of polymers in bands (10-12 $\mathrm{cm}$ wide) along the bottom of the irrigation furrow before irrigation (to a depth of $0-5 \mathrm{~cm}$ ) without a subsequent loosening and mixing of soil.

The study analyzed the efficiency of polymers K-4 and K-9, which represented a solution of polyacrylonitrile hydrolyzed in alkaline medium. Polymers contained $10 \%$ of active ingredient. The experiments were conducted on a plot of $288 \mathrm{~m}^{2}(60 \mathrm{~m} \times 4.8 \mathrm{~m})$, with 4-fold replications located along a slope in the same soil layer. Watering was done under the flow rate of $0.5 \mathrm{l} / \mathrm{s}$.

\section{Results and discussion}

The studies revealed that active deformation of the leading part of the furrow took place during the period of irrigation. The contents of humus and nitrogen at the heavily washed upper and middle parts decreased and they increased at the washed lower part of the slope. For example, the composition of humus in the $0-10 \mathrm{~cm}$ horizon at the upper and middle parts of the slope in the gray brown soils was $2.29 \%$ and $2.14 \%$, respectively; the composition of total nitrogen was $0.18 \%$ and $0.172 \%$, respectively; whereas at the lower part, the composition was $2.47 \%$ and $0.195 \%$ for humus and total nitrogen, respectively. Grain size composition of soils at all parts of the slope was represented by heavy loam. The composition of physical clay was $51.65 \%, 56.43 \%$ and $56.69 \%$ for the upper, middle, and lower parts of the slope, respectively.

For the light gray soils in the arable horizon, the humus contents in the washable and accumulation zones were $1.12 \%$ and $1.3 \%$, respectively; and the contents of total nitrogen were $0.078 \%$ and $0.098 \%$, respectively. The soils belonged to light loamy soil.

The result indicated that the treatments of K-4, K-9 and $\mathrm{PGK}+\mathrm{AA}$ had better absorption of irrigation water Soil erosion resistance caused by irrigation water increased so that there was no mud in the soil. Observations showed that on the surface layer of the bottom of the furrow treated by $\mathrm{K}-4$ and $\mathrm{PGK}+\mathrm{AA}$, there was no deformation during the irrigation period.

Our study showed the potential ability of soil resistance to the driving force of water flow. Processing of the upper soil layer $(0-5 \mathrm{~cm})$ with polymers increased the content of water-resistant aggregates $(>0.25 \mathrm{~mm})$ in the soil, improved water penetration, created a high roughness of the furrow bed, reduced the speed of the water flow and completely prevented the washing of the soil during crop irrigation.

Thus, in the control the contents of water-resistant aggregates $(>0.25 \mathrm{~mm})$ in the upper layer $(0-5 \mathrm{~cm})$ of the soil before irrigation were $32.4 \%, 36.7 \%$ and $39.8 \%$ at the upper, middle and lower parts of the furrow, respectively. With the K-4 treatment, the contents increased up to $79.0 \%, 76.4 \%$ and $71.0 \%$, respectively; and with PGK+AA treatment, the values were $71.0 \%$ (for the upper part of the furrow) and 68.5\% (for the lower part of the furrow). After the irrigation with a flow rate of $0.51 / \mathrm{s}$, the content of water-resistant aggregates in the control treatment decreased by $12.3 \%$ in the wash-off area and by $8.8 \%$ in the accumulation area; while in the option with K-4 treatment, the contents of water-resistant aggregates were $65.0 \%$ and $64.6 \%$ in the wash-off area and the accumulation area, respectively; and with $\mathrm{PGK}+\mathrm{AA}$ treatment, the content was $56.3 \%$. After 3 rounds of watering, the quantity of water-resistant aggregates in the soil treated with polymers had decreased. This is apparently because some of the aggregates collapsed during the irrigation and post-irrigation treatments. Consequently, one-time introduction of preparations in these doses did not provide irrigation wash-off during the growing season, and repeated application is needed.

At the end of the growing season, the content of water-resistant aggregates in the wash-off area was $15.4 \%$ in the control, and the contents were $36.5 \%$ and $34.2 \%$ with treatments $\mathrm{K}-4$ and $\mathrm{PGK}+\mathrm{AA}$, respectively. According to the water resistance of the soil structure, the water consumption and soil parameters in the furrow were listed (Table 1). 
Table 1 Water consumption and soil parameters in the irrigation furrow treated with polymers

\begin{tabular}{|c|c|c|c|c|c|c|c|}
\hline Soil type & $\begin{array}{c}\text { Type and } \\
\text { dose of } \\
\text { polymers }\end{array}$ & Texture & $\begin{array}{c}\text { Average diameter of } \\
\text { water-resistance } \\
\text { aggregates }(\mathrm{mm})\end{array}$ & $\begin{array}{l}\text { Soil weight } \\
\left(\mathrm{t} / \mathrm{m}^{3}\right)\end{array}$ & $\begin{array}{c}\text { Total } \\
\text { porosity }(\%)\end{array}$ & $\begin{array}{c}\text { Bottom } \\
\text { permissible } \\
\text { speed }(\mathrm{m} / \mathrm{s})\end{array}$ & $\begin{array}{c}\text { Permissible } \\
\text { water expendi- } \\
\text { ture }(1 / \mathrm{s})\end{array}$ \\
\hline \multirow{3}{*}{$\begin{array}{l}\text { Gray-brown soil } \\
\text { (slope } i=0.02 \text { ) }\end{array}$} & Control & & 0.60 & 2.65 & 53 & 0.062 & 0.13 \\
\hline & K-4 $(0.05 \%)$ & Heavy loam & 2.30 & 2.72 & 59 & 0.200 & 1.10 \\
\hline & $\mathrm{PGK}+\mathrm{AA}(2.0 \%)$ & Heavy loam & 2.90 & 2.69 & 58 & 0.230 & 1.25 \\
\hline \multirow{3}{*}{$\begin{array}{l}\text { Gray light soil } \\
\text { (slope } \mathrm{i}=0.005 \text { ) }\end{array}$} & Control & & 0.30 & 2.67 & 53 & 0.052 & 0.32 \\
\hline & K-4 $(0.05 \%)$ & Light loam & 1.71 & 2.70 & 59 & 0.160 & 2.08 \\
\hline & K-9 $(0.05 \%)$ & Light loam & 1.80 & 2.72 & 59 & 0.170 & 2.15 \\
\hline
\end{tabular}

The study of the chemical properties of soils treated with PGK+AA showed that the humus contents of soil increased from $2.38 \%$ to $3.83 \%$, total nitrogen contents from $0.05 \%$ to $0.11 \%$, hydrolysable nitrogen concentrations from 298.7 to $306.3 \mathrm{mg} / \mathrm{kg}$. The biogenic feature of the soil increased.

The estimation of irrigation wash-off of gray-brown soil was carried out by determining the turbidity of the flow in residual water. The results showed that the applied treatments sharply increased the erosion resistance of the soil. Thus, the turbidity of water in the control with a water flow rate of $0.51 \mathrm{l} / \mathrm{s}$ within 1 hour after the start of the discharge reached $17.02 \mathrm{~g} / \mathrm{L}$, and the values were 2.2 and $2.5 \mathrm{~g} / \mathrm{L}$ with treatments of K-4 and $\mathrm{PGK}+\mathrm{AA}$, respectively. Outside the irrigated fields with structured soil, the contents of washing humus and total nitrogen by discharge water were $1.89 \%-1.92 \%$ and $0.19 \%-0.20 \%$, respectively.

Under the influence of polymers on the bottom of the furrow, the gritty structured soil was formed, which reduced the speed of irrigation flow in the middle part from $0.3 \mathrm{~m} / \mathrm{s}$ (control) to $0.2 \mathrm{~m} / \mathrm{s}$. As our observations showed, water in the treatments, under which bottom furrows was wetted with solutions of polymers, flowed more slowly, but in a broader stream, provided better watering of the furrow ridges.

Irrigated light gray soils had low water resistance capacity, bringing about greater erosion and more wash-off. The structureless gray soils could be given a well-defined macrostructure by using chemical agents K-4 and K-9, which was the solution of polymers dissolvable in water; and after the wetting of soil treated with polymers, the soil was better structured and thus created a high anti-erosion effect.
The irrigated soils in the gray soil zone were characterized by low water resistance of aggregates and weak erosion resistance. After the treatment with a solution of K-4 and K-9 in the $0-5 \mathrm{~cm}$ soil layer, the quantity of water-resistance macroaggregates increased by $7-10$ times, and the content of aggregates (>1 mm) by $16-30$ times. Thus, in the first experiment, the content of water-stable macroaggregates for the $\mathrm{K}-4$ application of $15 \mathrm{~kg} / \mathrm{hm}^{2}$ increased from $3 \%$ (control) to $31 \%$, while for the K-4 application of 30 $\mathrm{kg} / \mathrm{hm}^{2}$, it increased from $3 \%$ to $36 \%$. Structure-forming effect was slightly lower in the application of K-9 than in the application of K-4. In the K-9 application of $20 \mathrm{~kg} / \mathrm{hm}^{2}$ in the first experiment, the aggregation of soil was increased to $22 \%$, and in the K-9 application of $40 \mathrm{~kg} / \mathrm{hm}^{2}$ up to $31 \%$.

It was determined that watering the bottom surface of irrigation furrows with the solution of preparations significantly increased soil stability and dramatically decreased the rate of irrigation spray, which caused irrigation wash-off during irrigation. Observations showed that the rate of irrigation flow reduced from $0.25 \mathrm{~m} / \mathrm{s}$ in the control to $0.17-0.13 \mathrm{~m} / \mathrm{s}$ where the bottom of the furrow before irrigation was moistened with the solution of polymers. On the third day after irrigation, the supply of moisture in the 1-m soil layer (where the bottom of the furrow was treated with polymer K-4 before irrigation) was higher compared with the control in the $2.5-3.0 \mathrm{~m}$ soil layer. Reduction in the speed of the irrigation stream and increased water absorption by soil under the influence of watering the bottom of the furrow with a solution of K-4 led to a sharp decrease in irrigation soil erosion (Table 2). 
Table 2 Irrigation wash-off of the light gray soil in the treatments of K-4 and K-9

\begin{tabular}{crrrr}
\hline & \multicolumn{3}{c}{ Wash-off $\left(\mathrm{t} / \mathrm{hm}^{2}\right)$} & \\
\cline { 2 - 4 } Treatments & \multicolumn{1}{c}{$1^{\text {st }}$} \\
irrigation & $\begin{array}{c}2^{\text {nd }} \\
\text { irrigation }\end{array}$ & $\begin{array}{c}3^{\text {rd }} \\
\text { irrigation }\end{array}$ & \\
\hline Control & 24 & 20 & 18 & 62 \\
$\mathrm{~K}-4\left(15 \mathrm{~kg} / \mathrm{hm}^{2}\right)$ & 7 & 5 & 5 & 17 \\
$\mathrm{~K}-4\left(30 \mathrm{~kg} / \mathrm{hm}^{2}\right)$ & 5 & 3 & 2 & 10 \\
$\mathrm{~K}-9\left(20 \mathrm{~kg} / \mathrm{hm}^{2}\right)$ & 6 & 5 & 4 & 15 \\
$\mathrm{~K}-9\left(40 \mathrm{~kg} / \mathrm{hm}^{2}\right)$ & 7 & 6 & 5 & 18 \\
\hline
\end{tabular}

These data showed that the soil in the control was characterized by high potential for wash-off. After irrigation, 18-24 t/hm $\mathrm{hm}^{2}$ soil was washed away, and the total wash-off for the three irrigations was $62 \mathrm{t} / \mathrm{hm}^{2}$ soil. Application of K-4 in the dose of $15 \mathrm{~kg} / \mathrm{hm}^{2}$ reduced the wash-off to17 t/hm ${ }^{2}$, and in the dose of 30 $\mathrm{kg} / \mathrm{hm}^{2}$ to10 $\mathrm{t} / \mathrm{hm}^{2}$. Compared with the control, the application of K-9 also provided a reduction of 15-18 $\mathrm{t} / \mathrm{hm}^{2}$ (Table 2). Watering the bottom of the furrow before irrigation sharply increased the erosion resistance of the soils. At the same time, the loss of irriga- tion water and the discharge of nutrients, particularly nitrate and ammonia nitrogen, reduced (Table 3).

Discharge of water in experiment 1 decreased from 625 to $163-178 \mathrm{~m}^{3} / \mathrm{hm}^{2}$ for K-4 and to $197-264$ $\mathrm{m}^{3} / \mathrm{hm}^{2}$ for K-9. Similar results were obtained in experiment 2, where the water discharge in the control was $561 \mathrm{~m}^{3} / \mathrm{hm}^{2}$ and that with the treatment in plots ranged from 375 to $406 \mathrm{~m}^{3} / \mathrm{hm}^{2}$. Discharge of nitrate in the control was $9.8-10.9 \mathrm{~kg} / \mathrm{hm}^{2}$, and in the treatments $0.1-0.2 \mathrm{~kg} / \mathrm{hm}^{2}$. In other words, the loss of nitrate and ammonia nitrogen has reduced by dozens of times and the wash-off of nutrients from the soil after the application of polymers in the furrow bottom has practically stopped (Table 3 ).

Usually, because of the high cost of preparations, polymers for building soil structure are insufficiently used in practice. However, our data showed that the increase of corn green biomass was significantly higher in K-4 and K-9 than in control. In addition, the protection of irrigated soils from irrigation erosion conserved the soil and its fertility (Table 4).

Table 3 Losses of nitrate and ammonia nitrogen by water discharge

\begin{tabular}{lcccccc}
\hline & & \multicolumn{5}{c}{ Treatment } \\
\cline { 3 - 7 } & & Control & $\mathrm{K}-4\left(15 \mathrm{~kg} / \mathrm{hm}^{2}\right)$ & $\mathrm{K}-4\left(30 \mathrm{~kg} / \mathrm{hm}^{2}\right)$ & $\left.\mathrm{K}-9(20 \mathrm{~kg} / \mathrm{hm})^{2}\right)$ & $\mathrm{K}-9\left(40 \mathrm{~kg} / \mathrm{hm}{ }^{2}\right)$ \\
\hline \multirow{3}{*}{ Experiment 1 } & Water $\left(\mathrm{m}^{3} / \mathrm{hm}^{2}\right)$ & 625 & 163 & 178 & 264 & 197 \\
& Nitrate $\left(\mathrm{kg} / \mathrm{hm}^{2}\right)$ & 10.9 & 0.1 & 0.5 & 0.1 & 0.1 \\
& Ammonia $\left(\mathrm{kg}^{2} \mathrm{hm}^{2}\right)$ & 15.2 & 0.3 & 0.1 & 0.2 & 0.1 \\
& Water $\left(\mathrm{m}^{3} / \mathrm{hm}^{2}\right)$ & 561 & 375 & 382 & 406 & 385 \\
Experiment 2 & Nitrates $\left(\mathrm{kg} / \mathrm{hm}^{2}\right)$ & 9.8 & 0.2 & 1.0 & 0.2 & 0.2 \\
& Ammonia $\left(\mathrm{kg} / \mathrm{hm}^{2}\right)$ & 13.6 & 0.7 & 0.2 & 0.5 & 0.2 \\
\hline
\end{tabular}

Table 4 Effectiveness of the application of polymers in increasing corn green biomass in light gray soils

\begin{tabular}{cccc}
\hline Indicator & Control & K-4 & K-9 \\
\hline Corn yield capacity $\left(\mathrm{t} / \mathrm{hm}^{2}\right)$ & 27.5 & 37.9 & 36.1 \\
Increasing biomass $\left(\mathrm{t} / \mathrm{hm}^{2}\right)$ & - & 10.4 & 8.6 \\
\hline
\end{tabular}

The treatment of the bottom of the irrigation furrow with solutions of K-4, K-9 and PGK+AA are important application in the control of irrigation erosion in irrigated plots. It works to improve the soil moisture regime, to reduce the loss of nutrients, and to create favorable conditions for the growth and development of agricultural crops.

\section{Conclusions}

The change of the physical properties of soils through the application of polymeric compounds provides a fundamental method to reduce water erosion and, therefore, to restore and improve soil fertility. The application of polymeric preparations facilitates their widest use in the control of water erosion. At the same time, a variety of preparations and the lack of uniform methods to evaluate the anti-erosion efficiency of polymers significantly complicate the process of generalizing and analyzing the results of numerous stud- 
ies and prevent the widespread use of polymeric preparations in agricultural production.

\section{Acknowledgements}

The research was supported by the International Science \& Technology Cooperation Program of China (2010DFA92720) and the Department of Ecology in Kazakh Research Institute of Soil Science and Agrochemistry named after Uspanov, Almaty, Kazakhstan.

\section{References}

Arinushkina E V. 1970. Guidelines for Chevical Analysis of Soils. Moscow: Moscow State University, 475.

Gusak V B. 1961. Influence of humic and polymeric preparations on physical properties of soil. In: Humic and Polymer Products in Agriculture. Tashkent: Academy of Science Ubekistan, 52-76. Ismatov D.1962. Effect of artificial structure builder K-4 on the resistance of irrigated common gray soils erosion. Journal of Agriculture in Uzbekistan, 162: 5-6.

Kaczynski N A, Mosolova A I, Taymurazova L H. 1967. Use of polymers for soil structuring and reclamation. Journal of Soil Science, 12: 98-106.

Khamdamov H H. 1973. Irrigation erosion and its control in the Zerafshan. PhD. Dissertation. Uzbekistan, University of Samarkand, 23.

Kuznetsov M S. 1981. Anti-erosion Resistance of Soils. Moscow: Moscow State University, 135.

Matyunin N F. 1965. Polymers in irrigational soil erosion control. Journal Cotton, 1: 44-45.

Namzhilov N B, Cybenov Y B. 2004. Polymers' impacts to the aggregate structure of chestnut soils of the West Baikal. Journal of Soil Science, 10: $1259-1263$.

Parakshina E M, Saparov A S, Mirzakeev E K. 2010. Soil Erosion in Kazakhstan. Almaty: LTD Poligraphy-service, 366.

Shadraimova K I. 2002. Fertility of the eroded grey soils of Tashkent oasis and application of " $\mathrm{K}$ " group preparations for combat with the erosion of irrigated soils. In: Problems of Genesis, Fertility, Melioration, Soil Ecology, Soil Resource Evaluation. Almaty: LTD Thesis, 270-271. 